\title{
Collaborative competency in physiotherapy students: Implications for interprofessional education
}

\author{
J Manilall, MSc (Physiotherapy); M Rowe, PhD (Physiotherapy) \\ Department of Physiotherapy, Faculty of Community and Health Sciences, University of the Western Cape, Cape Town, South Africa
}

Corresponding author: M Rowe (mrowedr@gmail.com)

Background. It has been suggested that improved collaborative competency in multidisciplinary teams may help understand how health professionals can address problems that no single-disciplinary expert can manage independently.

Objective. To describe the development of the ability to collaborate in a South African university physiotherapy department.

Methods. Focus group discussions and interviews were conducted with 3rd- and 4th-year physiotherapy students and lecturers, respectively. Participant responses were analysed thematically and evaluated against a self-developed framework that described the key and enabling competencies in collaboration. Results. The study found that students and lecturers had a basic understanding of collaboration, but lacked a more comprehensive perspective. Students and lecturers suggested that group work had the potential to develop collaborative competency, but expressed concerns about task design and implementation. While interprofessional education was a required component of the curriculum, both students and lecturers questioned the value of the module as it related to collaboration. Finally, challenges to the development of collaborative competency in the clinical context were highlighted. Conclusion. The study found that the development of collaborative competency, while recognised as important for addressing complex health needs, had several challenges that need to be addressed in order to be effective. Recommendations are provided for curriculum developers.

Afr J Health Professions Educ 2016;8(2 Suppl 2):217-221. DOI:10.7196/AJHPE.2016.v8i2.841

While advances in healthcare have led to an increase in life expectancy in the global population, ${ }^{[1]}$ it is evident that health systems are under pressure to address additional challenges such as globalisation, the emergence of new infections, and an increase in chronic disease, poverty and inequity. ${ }^{[2,3]}$ With the healthcare needs of the world becoming increasingly complex, new, sustainable and dynamic approaches to healthcare are necessary if we are to improve global health outcomes. ${ }^{[4]}$ The development of core competencies in health professions education, aligned with global health needs, ${ }^{[2]}$ has been suggested as one way in which health outcomes may be improved. ${ }^{[1,2,5]}$ However, professional education is struggling because of poor teamwork, as well as a mismatch between health professionals' competencies and the needs of the patient and the population. ${ }^{[2]}$

The ability to collaborate as part of a team is a core professional competency that produces positive health outcomes for patients, ${ }^{[6,7]}$ as no single discipline can meet all patient and population needs in a complex health system. ${ }^{[8]}$ Furthermore, collaboration is an essential component of safe, high-quality patient care. ${ }^{[9]}$ This suggests that health professions education must ensure that the ability to collaborate is intentionally developed in undergraduate students and that we must move away from professional silos to work effectively together. ${ }^{[2,10]}$ Health professionals must therefore understand each other's roles and responsibilities, share knowledge, work together in interdependent teams ${ }^{[6,9]}$ and communicate effectively with each other, their patients, their patients' families and their communities. ${ }^{[6,8]}$

To effectively address the health needs of the population, the Medical and Dental Board (MDB) in South Africa (SA) has adopted a modified version of the CanMEDS physician competency framework ${ }^{[9]}$ to inform the training and education of medical doctors, dentists and clinical associates in the SA context. $^{[11]}$ The MDB has highlighted the development of the following roles in clinical practice: health practitioner, communicator, collaborator, leader and manager, health advocate, scholar and professional. ${ }^{[12]}$ The framework also suggests that clinicians should possess a set of key competencies that outline the behaviours and skills that graduates should display. ${ }^{[13]}$ In developing the role of collaborator in the MDB framework, the following key competencies were identified: $(i)$ the ability to participate effectively and appropriately in multicultural, interprofessional and transprofessional teams as well as teams in other contexts (the community included); and (ii) the ability to work effectively with other healthcare professionals to promote positive relationships and prevent, negotiate and resolve interpersonal conflict. ${ }^{[12]}$

There is consensus that the ability to collaborate across professional boundaries is therefore an important core competency for health professionals. $^{[10]}$ However, the education of health professionals is traditionally conducted in silos, with each profession developing its own set of competencies in relative isolation from others. Interprofessional education (IPE) must therefore be considered as part of a collaborative practice model of care ${ }^{[10]}$ In this process, students from different professional programmes learn together, with a view to enhancing collaboration and teamwork to improve patient care. This requires all members of the team to understand each other's roles and core competencies, and that they develop attitudes and behaviours that facilitate collaboration. Therefore, IPE must be considered as an essential step in the development of a collaborative health workforce. ${ }^{[10]}$

Health professions education provides the foundation for the development of any profession, with training institutes bearing the primary responsibility for the development of core competencies, which includes the ability to collaborate. ${ }^{[6]}$ However, there is no clear understanding of how health professions educators can develop or assess collaborative competency in undergraduate healthcare students. There have been calls for educational reforms to produce graduates with appropriate professional competencies, ${ }^{[2,14]}$ as healthcare education has not kept pace in meeting the demands of struggling health systems. ${ }^{[2,10]}$ This is evident by the fact that these professions do not effectively work well together ${ }^{[10]}$ possibly as a result of poor development of core competencies in undergraduate education. 
If healthcare professionals are to address the increasingly complex health needs of their client populations, it appears that the ability to collaborate effectively must be intentionally developed in undergraduate health professions curricula. In addition, it seems evident that IPE is an appropriate space within the curriculum in which to embed the development of collaboration as a core competency. However, there is limited research on the ways in which this important competency is developed in SA health professions students. The objective of this study was therefore to determine how students and lecturers in a physiotherapy department perceive the development of collaborative competency in the undergraduate curriculum.

\section{Methods}

The study made use of a descriptive, qualitative research design to gain insight into the learning and teaching experiences of students and lecturers in the Department of Physiotherapy, University of the Western Cape (UWC), as they related to the development of collaborative competency. The researcher (JM) used focus group discussions with undergraduate students and semi-structured interviews with lecturers to develop an understanding of how students in the department were being prepared for collaborative practice. ${ }^{[15,16]}$ All lecturers and all 3rd- and 4th-year undergraduate students were invited to participate in the study and the focus group participants were selected purposively. The 3rd- and 4th-year focus group discussions each included six students and were conducted by MR and JM respectively in June and July 2015.

To define the concept of collaboration for this study, the authors combined several competency frameworks: the CanMEDS physician framework, ${ }^{[9]}$ the Essential Competency Profile for Canadian physiotherapists, ${ }^{[17]}$ and the MDB competency profile ${ }^{[12]}$ to develop a single framework against which to evaluate student and staff responses. The framework used to describe collaborative competency in the context of this study is presented in Table 1.

Semi-structured interviews with seven lecturers from the department were conducted by JM in person or telephonically, with one follow-up interview conducted to obtain additional clarity from one participant. The data from the focus groups and interviews were audio recorded and transcribed verbatim, and then sent to participants for member checking to confirm their accuracy. The transcripts were initially read through several times by JM for familiarisation with the content. ${ }^{[18]}$ Participant responses to questions related to the development of collaborative competencies were then openly coded to create themes, providing the authors with a formal system for organising the data from each group. ${ }^{[19]}$ Themes from both groups were then compared to identify any links and relationships between them. Finally, the participant responses were evaluated against the key and enabling competencies in the framework presented in Table 1 to determine if collaboration as a core competency was being effectively developed in this group of students.

Permission to conduct the study was obtained from the Registrar of UWC, the Research Ethics Committee (registration No. 15/4/34), and the Head of the Physiotherapy Department. The identities of the participants were removed from the transcripts and all information remained confidential. Participants were provided with an information sheet describing the context for the study, and could withdraw at any stage without negative consequences.

\section{Results and discussion}

The results present the findings on students' and lecturers' perceptions of the development of collaborative competency in the physiotherapy department. Participant responses to questions are presented in sections, along with a discussion of the responses and emergent themes in relation to the framework presented in Table 1 . The questions posed to students and lecturers included the following: What is your understanding of collaboration? How is collaboration developed in the classroom? What are your perceptions of the IPE modules in your course? What are your perceptions of collaboration in the clinical context?

\section{Question: What is your understanding of collaboration?}

All participants were asked what they understood collaboration to mean in the context of professional education, to determine if they could identify the activities that were linked to its development. The theme that emerged from the responses was that participants had a basic understanding of collaboration as working together, although the students' discussion seemed to indicate deeper insight. Two lecturer responses are presented:

'... individuals who work together around a specific subject or topic with a common goal or outcome.' (Lecturer)

'Collaboration for me means working with another team or another set of people on a specific goal ... Collaboration is a big aspect of teamwork: (Lecturer)

However, students' responses seemed to suggest that they thought of collaboration as being something beyond simply working together:

'Putting ideas together to get to the best achievement [with the] specific goal to take care of this patient.' (Student)

'Usually when people collaborate, they bring their own unique ideas or they impart a bit of themselves into the project they are working along with others.' (Student)

Table 1. Framework describing collaboration as a competency

\begin{tabular}{|c|c|}
\hline Key competency & Enabling competency \\
\hline $\begin{array}{l}\text { Establishes and maintains interprofessional } \\
\text { relationships, which foster effective client- } \\
\text { centred collaboration }\end{array}$ & $\begin{array}{l}\text { Respecting and understanding the roles and responsibilities of other healthcare professionals towards patient- } \\
\text { centred care } \\
\text { Fostering collaboration with other relevant stakeholders in patient care }{ }^{[9,12,16]}\end{array}$ \\
\hline $\begin{array}{l}\text { Collaborates with others to prevent, manage } \\
\text { and resolve conflict }\end{array}$ & $\begin{array}{l}\text { Identifying issues that may result in conflict and employing collaborative skills to resolve them } \\
\text { Demonstrating a respectful attitude towards colleagues and the interprofessional team to foster positive relationships }{ }^{[9,12,16]} \\
\text { Reflecting on improving the functioning of the interprofessional team }{ }^{[12]}\end{array}$ \\
\hline $\begin{array}{l}\text { Effectively and safely transfers care to another } \\
\text { health professional }\end{array}$ & $\begin{array}{l}\text { Being able to assess when the patient should be transferred to another healthcare provider } \\
\text { Demonstrating the use of written and verbal communication for safe transfer }{ }^{[12]}\end{array}$ \\
\hline
\end{tabular}


Student participants were able to express the concept that collaboration included the use of knowledge and ideas to achieve a shared goal, while lecturers described it simply in the context of physically working together. ${ }^{[9,12]}$ Some students were also more expressive in their understanding of collaboration, including the idea that collaboration involves working with others to achieve a shared goal, but also including the integration of different ideas and of investing themselves in the work.

Both groups were therefore able to articulate a coherent and accurate description of what collaboration meant, which aligned with the first key competency in our description of collaboration in Table 1. In other words, this group understood that collaboration was about establishing and maintaining professional relationships that revolved around patient-centred care. However, in the context of the other key competencies presented in Table 1, neither students nor lecturers expressed an understanding of collaboration that went beyond 'working with others'. Neither group discussed the importance of being able to resolve conflict as part of a collaborative process, nor did they discuss the role of referral as a collaborative activity, highlighting a limited understanding of collaboration as a core competency for professional practice.

\section{Question: How is collaboration developed in the classroom?}

Both lecturers and students in this study emphasised the use of group work in classroom activities as being the primary means by which collaborative competency was developed. Within the classroom, group work was viewed by both students and lecturers as a means to develop collaboration, but the theme that emerged from these responses was that there was some uncertainty about specific aspects of group work. Lecturers in general seemed confident about their use of group work in the classroom, as expressed by the following participant:

'We do a lot of group work, we do a lot of group assignments as well and especially in the 1st and 2nd years we do encourage them to work together in groups ... ? (Lecturer)

However, one lecturer suggested that the structure of the group work determines how well students collaborate. Furthermore, the lecturer also expressed uncertainty about how to develop collaboration, questioning whether group work necessarily leads to collaboration:

'... I think in the classroom, if you want to develop collaboration you do need to be ... a little careful about what tasks you're going to give them ... I actually can't think of what tasks we'd give them to assist them with collaboration.' (Lecturer)

The following two responses, the first from a student and the second from a lecturer, highlight a major concern with group work, namely that co-operation is usually the default mode of work, instead of collaboration:

'They [the lecturers] don't say, hang on ... it's important that if you are not working together then this is useless ... I think we are taught in a way of co-operation ... instead of collaboration.' (Student)

'I'll break them [the students] up into groups and I'll give them a task to work on. And then I always ask them to divide themselves in terms of who will do what ... ? (Lecturer)

One student suggested a particular approach to group work that included the use of clinical case scenarios as part of the structure:

'I think it starts from case-based learning, that's how we started collaboration and group work .... ? (Student)
There was also a concern, expressed by both students and lecturers, that some students would not make a fair contribution to the activity, which influenced how enthusiastic they were about working in groups:

'You choose them for either how well they work in a group or they're not lazy or they play their part and you know that they're going to do the work.' (Student)

'... what tends to happen when you're in a group, you get one or two people that slack off.' (Student)

In terms of the development of collaboration in the classroom, both lecturers and students in this study identified group work as the only developmental activity that could lead to collaborative competency. However, there was some uncertainty about how the structure of the task within the activity determines how well students actually work together. True collaborative activity requires individuals to work together on a shared goal, where the work is characterised by a low division of labour, synchronous communication and negotiability. ${ }^{[20]}$

In this study, it was clear that while group work was identified by participants as a standard for developing collaborative competency, there were some concerns raised about how well this worked in practice. If the task in the group work activity is not well designed, it leads to a high division of labour, where tasks are split among students and completed individually, rather than working together. Finally, if students and lecturers are not convinced that group work is an effective means of developing collaborative competency because not all members contribute equally, they may not engage with the activity at an appropriate level.

In terms of the framework (Table 1), the students and lecturers were aware that group work may involve conflict between individuals if some students do not contribute to the activity, but neither group expressed any concern about how to manage this conflict, or that teaching students the skills required for conflict management should form part of the activity. In this sense they were lacking both key and enabling competencies that determine if collaboration will be effective.

\section{Question: What are your perceptions of the IPE modules in your course?}

Students in this course were required to attend interprofessional education modules and activities where they engaged with students from other health professions. Students presented contrasting views on the value of these IPE opportunities, especially in terms of developing collaborative competency. The theme that emerged from responses to this question was that students were frustrated with their lack of understanding of the roles of other health professionals. As seen in the example response below, some students did find an opportunity to engage with and learn from other healthcare students:

'... we obviously have to focus on the subject but we also get talking about your profession, my profession; what you do, what I do. And there we build up an understanding of each other and what we do.' (Student)

But these students were in the minority and most others in the focus group discussions reported that the IPE modules did not add to their understanding of the roles of other health professionals, as highlighted in the quotes below:

'In our 1st and 2nd years they focused a lot on integrating us as disciplines, but they didn't actually focus on getting each discipline to understand the roles of the [other] disciplines they're working with.' (Student) 
'No. I feel like I don't know everything about what exactly a speech therapist does or what exactly an OT [occupational therapist] does. I vaguely have learned through experience in the last 2 years.' (Student) 'Somewhere along the line we've got some form of a definition of each role of different professionals ... A definition is not exactly the same thing as describing roles.' (Student)

One of the lecturers also remarked on the lack of perceived value by the students in the IPE modules:

'When I talk to the students they actually just view the module as a waste of time; they don't view the module as something that they need .... ? (Lecturer)

Several students believed that the IPE modules had limited value for their training which, considering the important position of role understanding in effective collaboration, suggests that these students were not well prepared to work together with other health professions. While the clinical setting provides opportunities for students to collaborate within interdisciplinary teams, it also requires an understanding of the roles and responsibilities of all team members to be effective. ${ }^{[6,9]}$ IPE has been suggested as an approach to developing students' ability to collaborate so that they become more effective members of interprofessional teams. ${ }^{[21]}$ However, the theme that emerged from responses to this question was that many students were not sure if the IPE modules had any value with regard to their development; this is a concern because if students are not familiar with the roles of other members of the team, it influences how well they work together.

When evaluating this theme against the description of collaboration (Table 1), we see that an understanding of the role of other health professionals is an important enabling competency that underpins the ability to work effectively together. It would also affect students' ability to refer appropriately to other professionals, which is another key competency in the ability to collaborate. The students believed that they were not benefitting from the learning opportunities available in the IPE modules, especially in the context of role understanding for effective collaboration. If collaboration requires that health professionals understand each other's roles, there is a concern that this enabling competency was lacking in many students in this sample.

\section{Question: What are your perceptions of collaboration in the clinical context?}

Participant responses to this question were categorised into a theme of concern, with the lack of modelling of collaborative practice in the clinical context. While ward round attendance for students on clinical rotations were encouraged by clinicians, students were frustrated with the process. The students highlighted a lack of inclusion, which was perceived as a barrier to their learning and to developing collaborative competency.

'When the doctors do ward rounds and you are there, they speak to themselves and their students - like they don't involve anybody else, they don't even involve the patients.' (Student)

'They [the doctors] were running the show, talking, but within themselves about themselves.' (Student)

'When they did ward rounds in the ICU [intensive care unit], we kind of just walked with, but it felt like we were sneaking in to hear, I didn't feel like we were actually invited to be part of it, we were just there, we weren't part of it.' (Student)
Even though inclusion in ward rounds provides opportunities to develop interprofessional collaboration and teamwork, ${ }^{[22]}$ the students expressed a sense of exclusion as other healthcare professionals spoke among themselves, ignoring the students and therefore creating a barrier to interprofessional communication and teamwork. ${ }^{[6]}$ Moreover, the impact of clinicians' role-modelling in the development of collaboration among students was highlighted by students. Clinicians who modelled the ability to collaborate with other health professionals and who encouraged students to do likewise, promoted the development of collaboration:

'In my 3rd year I was encouraged by the clinician at the placement. She told me that if I needed to speak to anyone or any of the health disciplines, then I could pick up the phone and I could always phone them and ask them about my patients.' (Student)

In contrast, when a clinician wasn't confident enough to collaborate with others in the team, it influenced the student's perceptions of collaboration:

'If the clinician is also too scared to say something then you're like, "What are we going to do now?" So if she was more like, "You're right, as physios this is our right to speak ...". She was just too scared to say something.' (Student)

Lecturers agreed that clinicians had an influence as role-models in terms of showing students how to collaborate with others:

'The clinicians are working in silos when they are in hospitals or in the clinics, they are working separately. So it's difficult to say they would be pushing for collaboration in a clinical setting.' (Lecturer)

'Some clinicians at certain placements can actually be quite good [at rolemodelling collaboration]. But then I also think that some clinicians at other placements are not that good.' (Lecturer)

It seemed that if students perceived that a clinician's self-confidence within the team was low and that they were fearful of contributing to team discussions, this behaviour could be learned by the student. There is therefore a need for all healthcare professionals to be aware of their own behaviour as collaborators because students learn from observation. Besides interprofessional interactions, students also learn about collaboration through observation in the clinical environment, ${ }^{[23,24]}$ in particular via the role-modelling of clinicians. ${ }^{[22,24]}$ Confidence is an important precursor to interprofessional collaboration, ${ }^{[25]}$ influencing one's ability to communicate and collaborate within teams. ${ }^{[26]}$

\section{Recommendations}

It appears that deeper insight into a more comprehensive understanding of collaboration was lacking in both students and lecturers in the department, and that there is a need for changes to conceptual understanding and curriculum activities. In terms of the group work activities used to develop collaborative competency, lecturers should pay more attention to task design, ensuring that students do not simply co-operate and work on tasks separately as individuals. In addition, peer evaluations may be one way of motivating and assessing collaborative capabilities in group work to address concerns about some students not contributing. However, lecturers must inform students about the rationale for its use and familiarise them with the process for it to be effective. ${ }^{[20]}$

While students in this department experience their IPE modules in the classroom or campus context, there is evidence to suggest that IPE 
learning opportunities may have greater perceived value if they are conducted in the clinical setting. ${ }^{[25,26]}$ In this context, it may also improve students' understanding of the roles and responsibilities of fellow healthcare professionals. ${ }^{[25,26]}$ The physiotherapy department should therefore consider the integration of IPE activities into the clinical platform in addition to the campus-based modules that students currently attend. And, while logistically challenging because of timetable differences, students from different disciplines should be required to complete collaborative activities within a problem-based learning context ${ }^{[10]}$ over longer periods of time, as opposed to meeting for single-day seminars.

The concern about students' relative exclusion from ward rounds in clinical practice and its influence on their perception of collaborating in a team are suggestive of a larger issue. Changes to the social and organisational norms of institutions are not easily addressed owing to long-standing professional hierarchies that create a barrier to effective collaboration within healthcare teams. ${ }^{[6,23]}$ Increasing student awareness on how organisational systems influence interprofessional collaboration should also be an objective of the IPE programme. ${ }^{[23]}$

Finally, an innovation in teaching and learning strategy that could be considered for the development of collaborative competency in the IPE curriculum is to integrate e-learning into the programme. ${ }^{[10,27]}$ The integration of technology into the classroom is possible in resourceconstrained countries and may serve as a tool for enhancing IPE, particularly if delivered in an open-access environment. ${ }^{[10]}$ However, online tools for collaborative group work must be implemented with care, and student support is an essential component. ${ }^{[27]}$

\section{Conclusion}

This study provides insight into the development of collaboration among undergraduate students at an SA university physiotherapy department. Although students and lecturers have a basic understanding of the concept of collaboration, there are gaps in their deeper development, demonstrated by the lack of key and enabling competencies that were articulated by the group. While both lecturers and students recognised the value of group work as an opportunity to develop collaborative competency, there was uncertainty from both groups about specific aspects of its implementation. It was evident that the ability to collaborate, while articulated by both lecturers and students, was not intentionally developed in the programme.

The clinical environment and IPE modules are potentially important avenues to developing interprofessional collaborative abilities in physiotherapy graduates, but these aspects of the curriculum should be integrated more effectively. In particular, the use of group work to develop collaborative competency must include activities that help students develop skills in conflict resolution. The findings of this study have relevance for curriculum development in health professional courses, and the recommendations may help to graduate students with the key and enabling competencies to collaborate effectively between professions, within healthcare teams.

\section{References}

1. Chen L, Evans T, Anand S, et al. Human resources for health: Overcoming the crisis. Lancet 2004;364(9449):19841990. DOI:10.1016/S0140-6736(04)17482-5

2. Frenk J, Chen L, Bhutta ZA, et al. Health professionals for a new century: Transforming education to strengthen health systems in an interdependent world. Lancet 2010;376(9756):1923-1958. DOI:10.1016/S0140strengthen health

3. Labonté R, Mohindra K, Schrecker T. The growing impact of globalization for health and public health practice. Annu Rev Public Health 2011:32:263-283. DOI:10.1146/annurev-publhealth-031210-101225

4. Fried LP, Piot P, Frenk JJ, Flahault A, Parker R. Global public health leadership for the twenty-first century: Towards improved health of all populations. Glob Public Health 2012;7(Suppl1):S5-S15. DOI:10.1080/174416 92.2012.702118

5. Crosbie J, Gass E, Jull G, et al. Sustainable undergraduate education and professional competency. Aust Physiother 2002;48(1):5-7. DOI:10.1016/S0004-9514(14)60276-2

6. Interprofessional Education Collaborative Expert Panel. Core competencies for interprofessional collaborative practice: Report of an expert panel. Acad Med 2011;86(11):1351. DOI:10.1097/ACM.0b013e3182308e39

7. Suter E, Deutschlander S, Mickelson G, et al. Can interprofessional collaboration provide health human resources solutions? A knowledge synthesis. J Interprof Care 2012;26(4):261-268. DOI:10.3109/13561820.2012.663014

8. Suter E, Arndt J, Arthur N, Parbhoosingh J, Taylor ED, Siegrid D. Role understanding and effective communication as core competencies for collaborative practice. I Interprof Care 2009.23(1):41-51. DOI:10.1080/13561820802338579

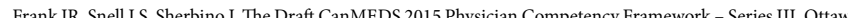
Frank JR, Snell LS, Sherbino J. The Draft CanMEDS 2015 Physicing
The Royal College of Physicians and Surgeons of Canada, 2014.

10. World Health Organization. Transforming and scaling up health professionals' education and training: World Health Organization Guidelines 2013. Geneva: WHO, 2013.

11. Van Heerden B. Effectively addressing the health needs of South Africa's population: The role of health professions education in the 21st century. S Afr Med J 2013;103(1):21-22. DOI:10.7196/SAMJ.646

12. Medical and Dental Board of the Health Professions Council of South Africa. Core competencies for undergraduate students in clinical associate, dentistry and medical teaching and learning programmes in Sout Africa. Pretoria: HPCSA, 2014

13. The Royal College of Physicians and Surgeons of Canada. CanMEDS Role: Collaborator. 2016. http://www. royalcollege.ca/rcsite/canmeds/framework/canmeds-role-collaborator-e (accessed 15 February 2016).

14. Senkubuge F, Modisenyane M, Bishaw T. Strengthening health systems by health sector reforms. Glob Health Action 2014;1(8):1-7. DOI:10.3402/gha.v7.23568

15. Kemparaj U, Chavan S. Qualitative research: A brief description. Indian J Med Sci 2013;67(3-4):89-98 DOI:10.4103/0019-5359.121127

16. McMillan W. Moving beyond description: Research that helps improve teaching and learning. Afr J Health Professions Educ 2010;2(1):3-7.

17. National Physiotherapy Advisory Group. Essential Competency Profile for Physiotherapists in Canada. 2009 http://www.physiotherapyeducation.ca/Resources/Essential\%20Comp\%20PT\%20Profile\%202009.pdf (accessed 15 January 2015)

18. Elo S, Kyngäs H. The qualitative content analysis process. J Adv Nursing 2007;62(1):107-115. DOI:10.1111/ j.1365-2648.2007.04569.x

9. Bradley EH, Curry LA, Devers KJ. Qualitative data analysis for health services research: Developing taxonomy, themes and theory. Health Serv Res 2007;42(2):1758-1772. DOI:10.1111/j.1475-6773.2006.00684.X

20. Dillenbourg P. What do you mean by 'collaborative learning?' In: Dillenbourg P, ed. Collaborative Learning Cognitive and Computational Approaches. Oxford: Elsevier, 1999:1-19.

21. Bridges DR, Davidson RA, Odegard PS, Maki IV, Tomkowiak J. Interprofessional collaboration: Three bes practice models of interprofessional education. Med Educ Online 2011;16:1-11. DOI:10.3402/meo.v16i0.6035

22. Morris R, Hilton J. Student placements - is there evidence supporting team skill development in clinical practice settings? J Interprof Care 2001;15(2):171-183. DOI:10.1080/13561820120039892

23. Pollard KC. Non-formal learning and interprofessional collaboration in health and social care: The influence of the quality of staff interaction on student learning about collaborative behaviour in practice placements. Learn the quality of stanf interaction on student learning about collaborative bet

24. Sheldon M, Cavanaugh JT, Croninger W, et al. Preparing rehabilitation healthcare providers in the $21 \mathrm{st}$ century: Implementation of interprofessional education through an academic-clinical site partnership. Work

25. Mellor R, Cottrel N, Moran M. 'Just working in a team was a great experience...' - Student perspectives on the learning experiences of an interprofessional education program. J Interprof Care 2013;27(1):292-297. DOI:10.3 109/13561820.2013.769093

26. O'Carroll V, Braid M, Ker J, Jackson C. How can student experience enhance the development of a model of interprofessional clinical skills education in the practice placement setting? J Interprof Care 2012;26(6):508-510. DOI: $10.3109 / 13561820.2012 .70920$

7. Rowe M. The use of a wiki to facilitate collaborative learning in a South African physiotherapy department. S Afr J Physiother 2012;68(2):11-16 